\title{
The Role of Spontaneous Polarization and the Thickness of Alignment Layers on the V-Shaped Switching in FLC Cells
}

\author{
V. Manjuladevi \\ Technological University Dublin \\ J.K. Vij \\ Technological University Dublin \\ Yuri Panarin \\ Technological University Dublin, yuri.panarin@tudublin.ie
}

Follow this and additional works at: https://arrow.tudublin.ie/engscheleart2

Part of the Electrical and Computer Engineering Commons

\section{Recommended Citation \\ This Article is brought to you for free and open access by the School of Electrical and Electronic Engineering at ARROW@TU Dublin. It has been accepted for inclusion in Articles by an authorized administrator of ARROW@TU Dublin. For more information, please contact arrow.admin@tudublin.ie, aisling.coyne@tudublin.ie, gerard.connolly@tudublin.ie.}

Manjuladevi, V. (2007). The role of spontaneous polarization and the thickness of alignment layers on the v-shaped switching in FLC Cells. Molecular Crystals and Liquid Crystals, vol. 477, pp.223/[717]-231/[725].

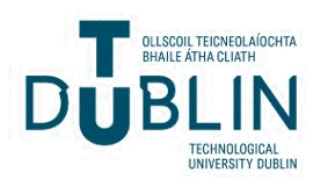




\title{
The Role of Spontaneous Polarization and the Thickness of Alignment Layers on the V-Shaped Switching in FLC Cells
}

\author{
V. Manjuladevi \\ J. K. Vij
}

Department of Electronic and Electrical Engineering, Trinity College

Dublin, University of Dublin, Dublin, Ireland

\section{Yu. P. Panarin}

Department of Electronic and Electrical Engineering, Trinity College

Dublin, University of Dublin, Dublin, Ireland; Department of

Electronic and Communication Engineering, Dublin Institute of

Technology, Dublin, Ireland

Ferroelectric liquid crystal mixtures with the various values of spontaneous polarizations were prepared, and the substrates were coated with different thicknesses of aligning agent. The frequency dependence of the electrooptic response of these materials in cells with various thickness of alignment layers has been measured. The coercive voltage as well as the contrast ratios are calculated. Our results support the "electrostatic model", according to which both the value of spontaneous polarization and the thickness of the alignment layer play important roles in the $V$-shaped switching.

\section{INTRODUCTION}

The thresholdless switching or the so-called V-shaped switching in Ferroelectric Liquid Crystals (FLC) is very attractive electro-optic effect for display applications and has been a topic of debate for almost a decade. Several theoretical models have been proposed to simulate conditions for observing this [1-6]. A number of experiments

We thank the Science Foundation of Ireland (SFI) grant (02/IN.1/I031) for funding the research work in Dublin. We thank Mr. I. Kobayashi of Nissan Chemical Industries Japan for the gift of the aligning agent (RN1175).

Address correspondence to J. K. Vij, Department of Electronic and Electrical Engineering, Trinity College Dublin, University of Dublin, Dublin 2, Ireland. E-mail: jvij@tcd.ie 
[3,7-11] have been carried out by different groups to confirm the various models. Optically active dopants involving chiral substituents of diesters of 4, 4"-terphenyl dicarboxylic acid have been found to have the same sign of $P_{s}$ but opposite helix handedness. Mixtures of some of these dopants have $P_{s}$ values higher than sum of their individual $P_{s}$ values and exhibit $\mathrm{SmC}^{*}$ over a wide range of temperatures. Loseva et al. [12] found that by mixing compounds 1 and 2 in the ratio 17.7 and $11.9 \%$ in the SmC matrix of 4-n-hexyloxyphenyl 4-n-octyloxybenzoate (HOPOOB), they obtained full helix compensation. We have used a different $\mathrm{SmC}$ matrix given in the experimental section and prepared helix compensated FLC mixtures with different concentration hence different $P_{s}$ values. We have conducted a detailed experimental study using these FLC mixtures to validate different theoretical approaches. Our study involves two different but related experiments: (a) with a material having a fixed spontaneous polarization $\left(P_{s}\right)$ of $\sim 100 \mathrm{nC} / \mathrm{cm}^{2}$ at $\sim 25^{\circ} \mathrm{C}$, and by varying the thickness of the alignment layer $\left(d_{a}\right)$ ranging from $40 \mathrm{~nm}$ to $400 \mathrm{~nm}$ and (b) fixing the thickness of the alignment layer $d_{a}$ at a maximum $(400 \mathrm{~nm})$ and using materials with the polarizations ranging from $25 \mathrm{nC} / \mathrm{cm}^{2}$ to $100 \mathrm{nC} / \mathrm{cm}^{2}$.

\section{EXPERIMENTAL}

In this work we mix the compounds 1 and 2 (Fig. 1) in the ratio of 17.7 and $11.9 \%$ and vary the total concentration of the dopants in the $\mathrm{SmC}$ matrix of 2-(4-n-decyloxyphenyl)-5-octylpuromidine and thus different $P s$ values are obtained. The sign of $P s$ is the same

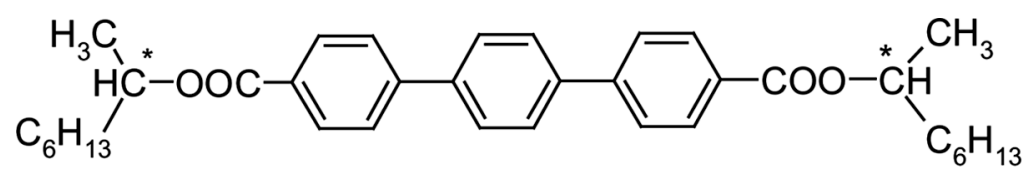

(1)

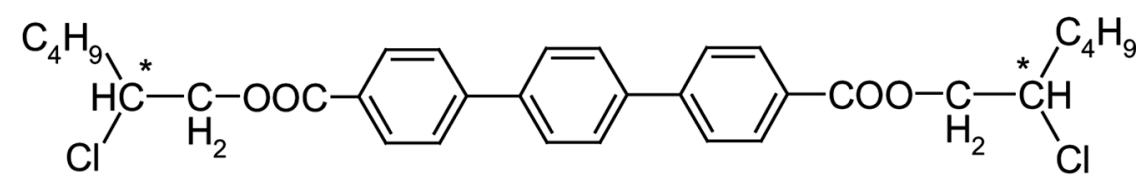

(2)

FIGURE 1 Molecular structures of the chiral dopants 1 and 2. 
but helices of the dopants are opposite and hence the obtained mixture is helically compensated. This mixture is further mixed with another $\mathrm{SmC}$ matrix (from 49 to 0 weight \%) to prepare a series of FLC mixtures with compensated helix (helix free) with various values of $P_{S}$ varying from $\sim 25 \mathrm{nC} / \mathrm{cm}^{2}$ to $100 \mathrm{nC} / \mathrm{cm}^{2}$. The spontaneous polarization was measured using the method described by Vaksman and Panarin [13]. For V-shaped switching studies planar cells were prepared using the Indium Tin Oxide (ITO) coated glass plates. The polyimide RN1175 (Nissan Chemicals, Japan) was used as the alignment layer. The alignment layer thickness was varied from $40 \mathrm{~nm}$ to $400 \mathrm{~nm}$ using the spin coating procedure. One side rubbed cells with thickness less than $2 \mu \mathrm{m}$ were prepared. The LC material was filled into the cell in the isotropic phase and then cooled down to room temperature. All the electro-optic measurements were carried out at room temperature. The sample was mounted on the stage of a polarised optical microscope between the crossed polarisers with the rubbing direction of the cell being parallel with one of the crossed polarisers. Triangular voltage was applied at various frequencies and the transmittance was measured using a photodiode attached to the microscope. The electro-optic response at various frequencies was recorded using an oscilloscope (Tektronix TDS 2014). The images in the dark state were recorded using a digital camera (Leica DFC480) connected to PC.

\section{RESULTS AND DISCUSSION}

The Spontaneous Polarisation measured as function of temperature for all the FLC mixtures prepared is shown in Figure 2. In Figure 3 are shown the electro-optic response of the material with $P_{s}=$ $96 \mathrm{nC} / \mathrm{cm}^{2}$ with various thickness of alignment layers. The electrooptic response shows V-shaped switching around $3 \mathrm{~Hz}$ in the cells with $d_{a}$ ranging from $400 \mathrm{~nm}$ to $200 \mathrm{~nm}$. V-shaped switching is no longer observed at $d_{a} \sim 100 \mathrm{~nm}$ and below. The domains start appearing as shown in Figure 7. In Figure 4 are shown the electro-optic response of the various mixtures with different $P_{s}$ ranging from $96 \mathrm{nC} / \mathrm{cm}^{2}$ to $24 \mathrm{nC} / \mathrm{cm}^{2}$ with alignment layer thickness of the cells being $400 \mathrm{~nm}$. The domains start appearing for the FLC mixture with $24 \mathrm{nC} / \mathrm{cm}^{2}$.

At higher frequencies electrooptic response shows positive hysteresis due to a delay in the switching. At low frequencies electrooptic response shows negative hysteresis due to the transport of ions in the cell. The effect of ions on the appearance of low frequency hysteresis has been explained using a simple mathematical model by Panarin et al. [1,7]. The electric field $E(t)$ inside a FLC cell is a sum 


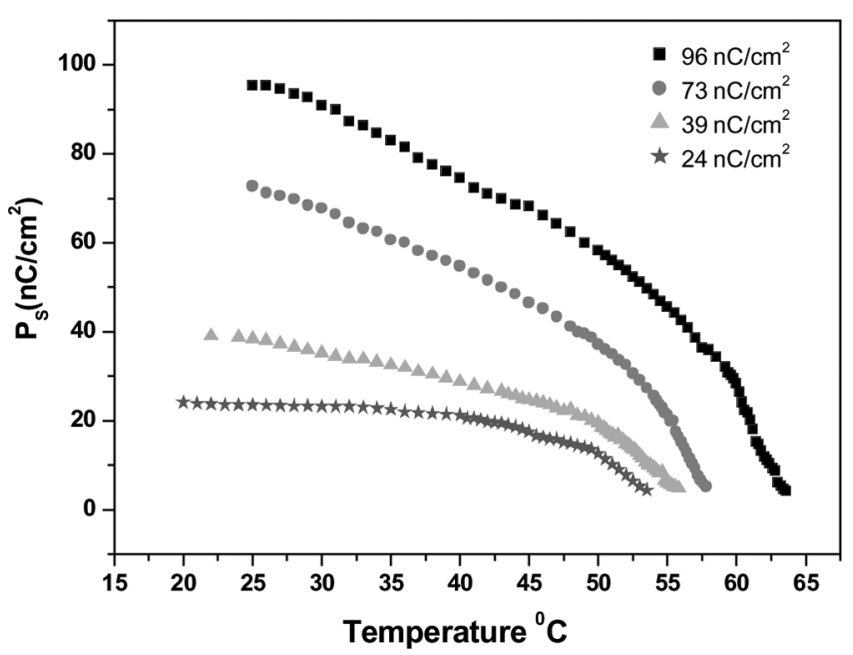

FIGURE 2 Temperature variation of the Spontaneous Polarization $P_{s}$ of the various FLC mixtures.

of the field due to the applied voltage and the field due to free charges distributed between the electrodes of the cell [1,7] and can be written as:

$$
E(t)=-\frac{V(t) \varepsilon_{a}}{2 d_{a} \varepsilon+d \varepsilon_{a}}+\frac{2 \sigma(t) d_{a}}{2 d_{a} \varepsilon+d \varepsilon_{a}}
$$

Where $V(t)$ is the triangular wave voltage applied across the FLC cell, $\varepsilon$ and $\varepsilon_{a}$ are dielectric permittivities of the LC and alignment layer respectively; $d$ and $d_{a}$ are the thickness of the LC cell and the alignment layer respectively. $\sigma(t)$ is the effective surface charge density that accumulates at the interface between the alignment layer and FLC, which can be written as

$$
\sigma(t)=\sigma_{\text {ion }}+P_{s}\left(e \cos \varphi_{1}+e \cos \varphi_{2}\right)
$$

$\sigma_{\text {ion }}$ is the charge density due to the ions and the second part is due to the polarisation charge density, $\phi_{1}$ and $\phi_{2}$ are the angles at the aligning surfaces. We observe that the $\mathrm{V}$-shaped switching gets distorted on lowering either spontaneous polarization or alignment layer thickness. This may be explained in terms of the enhancement of electrostatic energy. The electrostatic energy $\left(F_{e s}=P_{s} \cdot E\right)$ is proportional to $P_{s}^{2} \cdot d_{a}[1,6]$. 

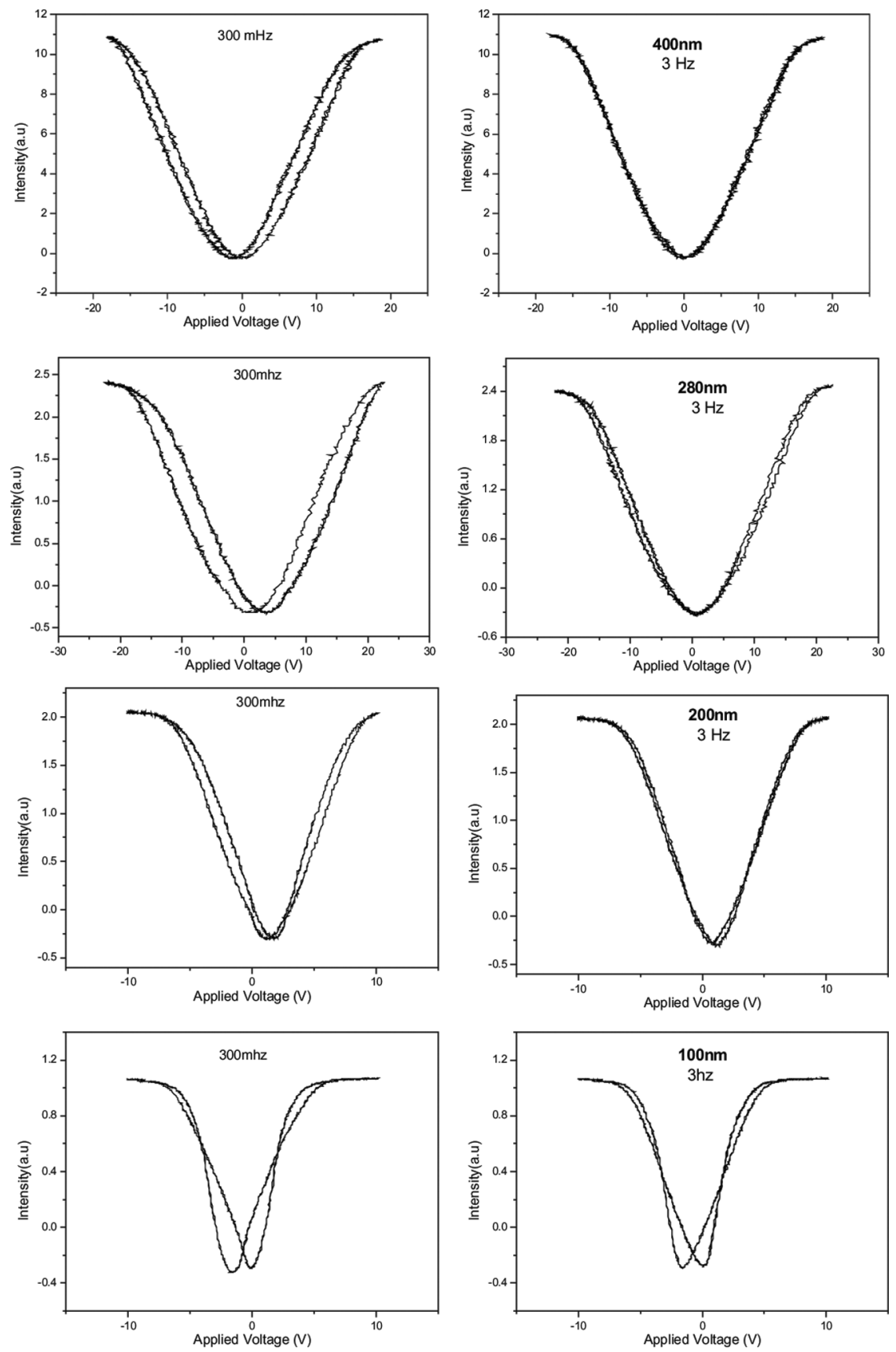

FIGURE 3 Electro-optic response of mixture with $P_{s}=96 \mathrm{nC} / \mathrm{cm}^{2}$ and by varying the thickness of alignment layers. 

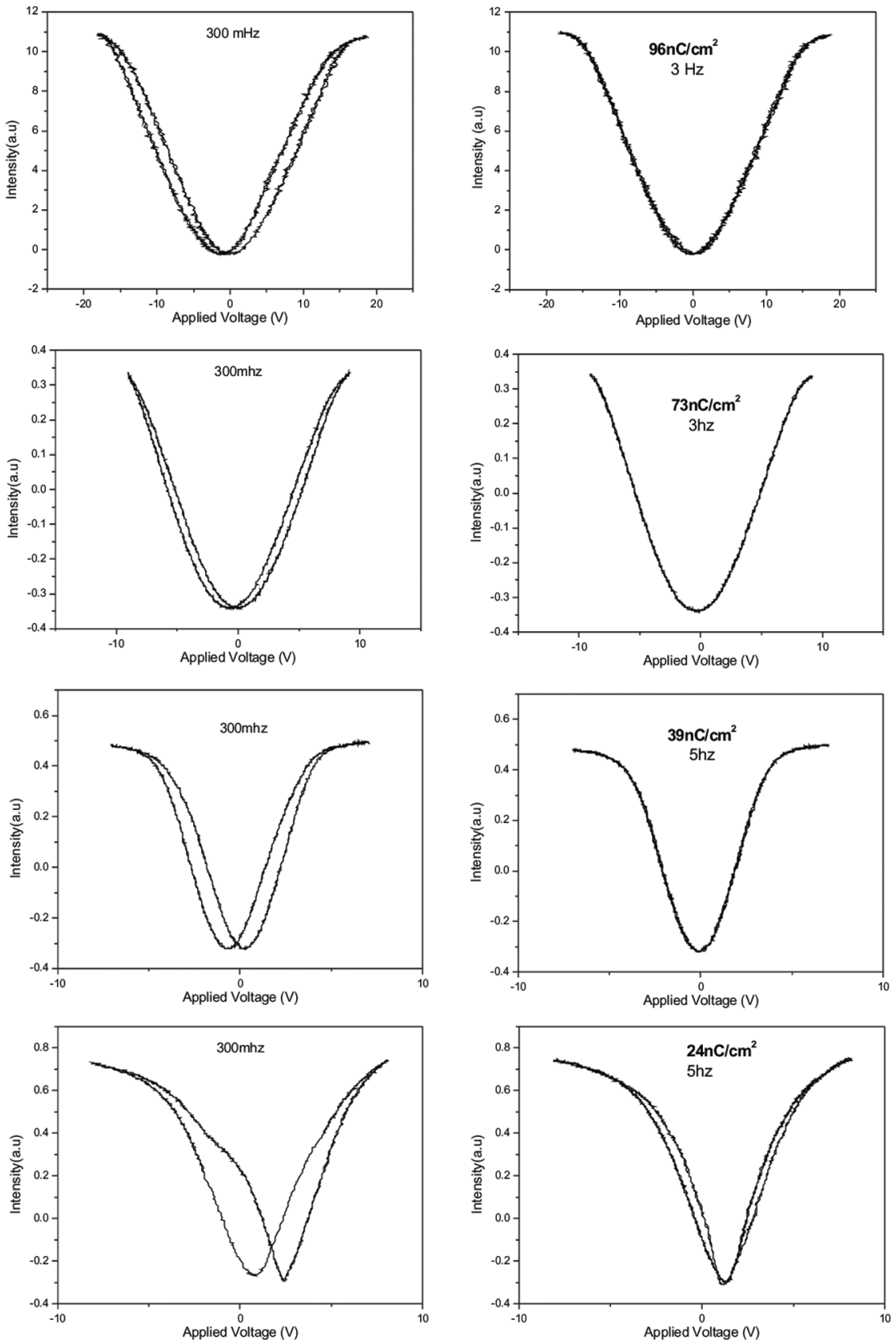

FIGURE 4 Electro-optic response of mixtures with fixed thickness of the alignment layer $d_{a} \sim 400 \mathrm{~nm}$ and by varying $P_{s}$. 


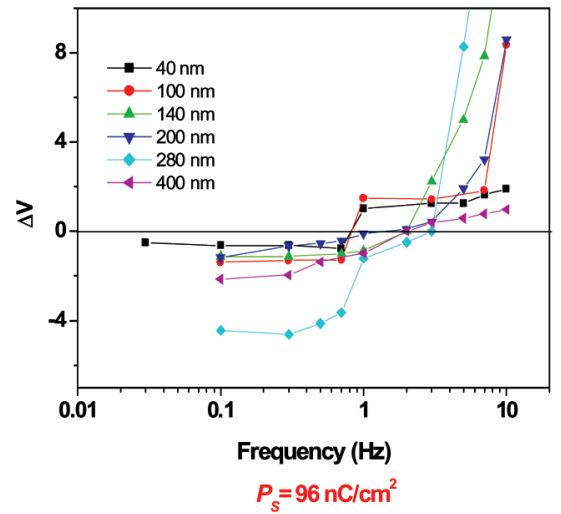

(a)

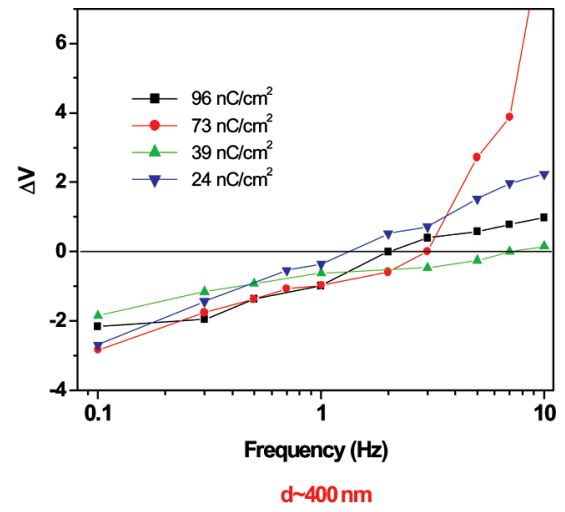

(b)

FIGURE 5 The variation of coercive field in both cases (a) and (b) as a function of frequency.

At high frequencies the field induced by conductivity ions enhance the externally applied field, and at low frequencies it diminishes that field. Hence the internal field can be either higher or lower than the field due to applied voltage, which leads to a change in coercive force [1]. The coercive voltage as a function of frequency for both the

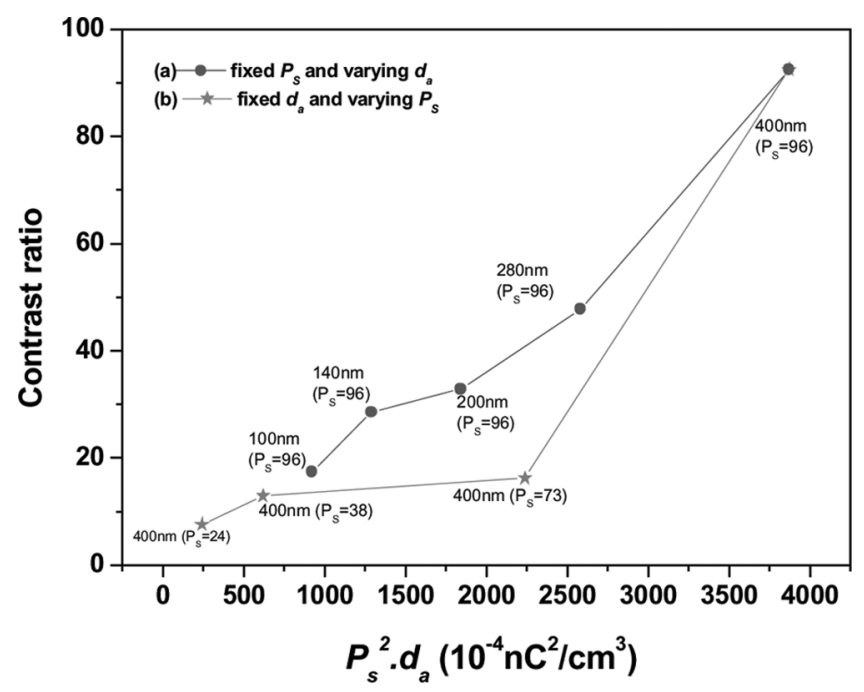

FIGURE 6 The contrast ratio in all the cases as function of $P_{s}^{2} \cdot d_{a}$. 

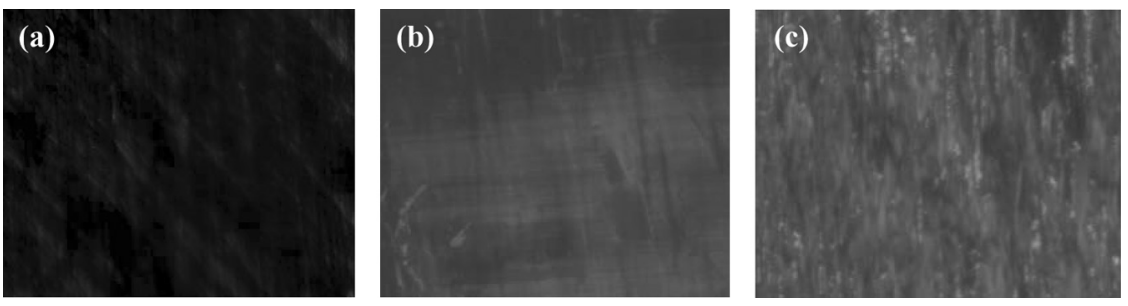

FIGURE 7 The images of textures of FLC in the field-off state (a) $P_{s}=$ $96 \mathrm{nC} / \mathrm{cm}^{2} ; d_{a} \sim 400 \mathrm{~nm}, \quad(b) P_{s}=96 \mathrm{nC} / \mathrm{cm}^{2} ; d_{a} \sim 100 \mathrm{~nm}$, and (c) $P_{s}=$ $24 \mathrm{nC} / \mathrm{cm}^{2} ; d_{a} \sim 400 \mathrm{~nm}$.

experiments are plotted in Figure 5. It can be clearly observed that the width of the $\mathrm{V}$-shaped switching response decreases with decreasing $P_{s}^{2} \cdot d_{a}$. The contrast ratio as a function of $P_{s}^{2} \cdot d_{a}$ is shown in Figure 6. The contrast ratio decreases with decreasing values of $P_{s}^{2} \cdot d_{a}$ and for values $<0.2 \mathrm{nC}^{2} / \mathrm{cm}^{3}$, the contrast ratio is reduced due to the appearance of the switching domains and the sample is no longer monostable.

\section{CONCLUSIONS}

This study supports the "electrostatic model" [1] (Boulder group) [6], according to which both the value of spontaneous polarization and the thickness of the alignment layer play important roles in the $\mathrm{V}$-shaped switching. We observe that the V-shaped switching gets distorted on lowering either spontaneous polarization or the alignment layer thickness. This may be explained in terms of the decrease in the electrostatic energy. The electrostatic energy $\left(F_{e s}=P_{s} \cdot E\right)$ is proportional to $P_{s}^{2} \cdot d_{a}$, where $P_{S}$ and $d_{a}$ are the values of the spontaneous polarization and the thickness of the alignment layer respectively. The contrast ratio decreases with decreasing values of $P_{s}^{2} \cdot d_{a}$ and for values $<0.2 \mathrm{nC}^{2} / \mathrm{cm}^{3}$, the contrast ratio is reduced significantly due to the appearance of the switching domains and the sample is no longer monostable. A search through the literature shows that Okano [14] for the first time showed that the elastic constant is significantly increased by increasing the spontaneous polarisation. This gives rise to increased stiffness to the $\mathrm{C}$ director as was later recognized by Rudquist et al. [3] and Clark et al. [4] for realizing the V-shaped switching. Hasegawa et al. [15] also discuss the importance of large Ps in realizing V-shaped switching with a constant ratio greater than 100 . 


\section{REFERENCES}

[1] Panarin, Yu. P. (1993). Mol. Mats., 1, 137.

[2] Inui, S., Iimura, N., Suzuki, T., Iwane, H., Miyachi, K., Takanishi, Y., \& Fukuda, A. (1996). J. Mater. Chem., 6, 671.

[3] Rudquist, P., Lagerwall, J. P. F., Buivydas, M., Gouda, F., Lagerwall, S. T., Clark, N. A., Maclenann, J. E., Shao, R., Coleman, D. A., Bardon, S., Bellini, T., Lnk, D. R., Natale, G., Glaser, M. A., Walba, D. M., Wand, M. D., \& Chen, X.-H. (1999). J. Mater. Chem., 9, 1257.

[4] Clark, N. A., Coleman, D., \& Maclennan, J. E. (2000). Liq. Cryst., 27, 985.

[5] Copic, M., Maclennan, J. E., \& Clark, N. A. (2001). Phys. Rev. E, 63, 031703.

[6] Copic, M., Maclennan, J. E., \& Clark, N. A. (2002). Phys. Rev. E, 65, 021708.

[7] Panarin, Yu. P., Panov, V., Kalinovskaya, O. E., \& Vij, J. K. (2000). Ferroelectrics, $246,35$.

[8] Hayashi, N., Kato, T., Ando, T., Fukuda, A., Kawada, S., \& Kondoh, S. (2003). Phys. Rev. $E, 68,011702$.

[9] Seomun, S., Park, B., Chandani, A. D. L., Hermann, D., Takansihi, Y., Ishikawa, K., Takazoe, H., \& Fukuda, A. (1998). Jpn. J. Appl. Phys., 37, L691.

[10] Blinov, L. M., Palto, S. P., Podogornov, F. V., Moritake, H., \& Haase, W. (2004). Liq. Cryst., 31, 61.

[11] Tzeng, S., Lin, T. Y., Haung, R. H., Wu, J., \& Wu, S. (2004). Phys. Rev. E, 70, 011712.

[12] Loseva, M., Chernova, N., Rabinovich, A., Pozhidaev, E., Narkevich, J., Petrashevich, O., Kazachkov, E., \& Korotkova, N. (1991). Ferroelectrics, 114, 357.

[13] Vaksman, V. M. \& Panarin, Yu. P. (1992). Mol. Mats., 1, 147.

[14] Okano, K. (1986). Jpn. J. Appl. Phys., 25, 1846.

[15] Hasegawa, R., Fujiware, H., Nagata, H., Hare, Y., Saishu, T., Fukushima, R., Akiyama, M., Okumara, H., \& Takatoh, K. (2000). J. SID, 9(2), 107. 